\title{
RESGATE DE TEXTOS GEOGRÁFICOS
}

\author{
João Carlos NUCCl ${ }^{1}$
}

A Revista RA'E GA - O ESPAÇO GEOGRÁFICO EM ANÁLISE, do Departamento e do Programa de Pósgraduação em Geografia da Universidade Federal do Paraná, reserva esta sessão para a divulgação de textos de relevância para os estudos geográficos apresentados em publicações esgotadas, em artigos fora do circuito geográfico ou comercial, e ainda textos apresentados em palestras e aulas inaugurais sem boa divulgação.

O texto que estamos apresentando, Paisagem e Geografia Física Global. Esboço metodológico, de autoria de G. BERTRAND, é uma tradução, realizada pela Profa Dra. Olga Cruz, do original Paysage et geographie physique globale. Esquisse méthodologique, publicado na "Revue Geógraphique des Pyrénées et du Sud-Ouest", Toulouse, v. 39, n. 3, p. 249-272, 1968. O texto traduzido foi publicado no Caderno de Ciências da Terra, número 13, do antigo Instituto de Geografia-USP (São Paulo/SP) em 1972.

Sendo uma das principais referências para todos aqueles que se interessam pelos estudos relacionados com a paisagem, achamos por bem resgatá-lo nesse número da revista, para facilitar sua consulta e reviver os debates sobre o conceito de paisagem e os métodos utilizados em sua classificação e avaliação como estudo teórico e como subsídio ao planejamento.

A paisagem, como um conceito científico introduzido por Alexander von Humboldt (1769-1859), o grande pioneiro da moderna Geobotânica e da Geografia Física, é resgatada por Bertrand como uma entidade holística corroborando, assim, as idéias de Troll que na década de 1930 lançara as bases da Ecologia da Paisagem, método que representou um progresso sobre os estudos fragmentados, por tentar reagrupar todos os elementos da paisagem sem se esquecer do ser humano.

Na procura por uma síntese da paisagem o autor afirma, categoricamente, que seria necessário renunciar a determinar unidades sintéticas com base nas unidades elementares delimitadas pelas disciplinas mais especializadas (Geologia, Geomorfologia, Pedologia, Climatologia, etc), mas que, ao contrário, seria preciso procurar talhar diretamente a paisagem global tal qual ela se apresenta, enfatizando que "a síntese vem felizmente no caso substituir a análise"; uma questão de difícil entendimento para nossa visão ainda fragmentada.

Bertrand discute um sistema taxonômico que permitiria classificar as paisagens em seis níveis temporoespaciais (zona, domínio, região, geossistema, geofácies e geótopo), sendo cada nível considerado uma "unidade de paisagem" definida em função da escala.

No quadro apresentado no texto, o autor coloca, para cada nível escalar (unidade de paisagem), exemplos franceses que podem ser relacionados com os exemplos fornecidos pelo Prof. Dr. Felisberto Cavalheiro para as paisagens do Rio de Janeiro e de São Paulo e por nós para o Paraná ${ }^{2}$, como mostra o quadro 1.

1 Professor doutor do Departamento de Geografia da Universidade Federal do Paraná.

2 O professor Felisberto Cavalheiro (1945-2003) ministrava a disciplina Teoria Geográfica da Paisagem no Departamento de Geografia da USP e, ao trabalhar com o texto do Bertrand, procurava adaptar os exemplos para a realidade brasileira. Atualmente, ministro uma disciplina com o mesmo título para a graduação em Geografia da UFPR e, além de utilizar os exemplos do professor Felisberto, apresento outros relacionados com as paisagens paranaenses. 
QUADRO 1 - EXEMPLOS DE UNIDADES DE PAISAGEM PARA O RIO DE JANEIRO, SÃO PAULO E PARANÁ FORNECIDOS EM SALA-DE-AULA NA DISCIPLINA TEORIA GEOGRÁFICA DA PAISAGEM (ORG. NUCCI, 2004). EXAMPLES OF LANDSCAPE UNITS FOR RIO DE JANEIRO, SÃO PAULO AND PARANÁ FROM A CLASS TASK FROM GEOGRAPHIC LANDSCAPE THEORY COURSE

QUADRO 2 - SISTEMA DE CLASSIFICAÇÃO TÊMPORO-ESPACIAL DAS PAISAGENS DA FLORESTANACIONAL DE IPANEMA, IPERÓ/SP, COM BASE EM BERTRAND (1971, p. 12; ORG.: ORIANA AP. FÁVERO - 2004). SYSTEM OF TIMESPATIAL CLASSIFICATION OF IPANEMA NATIONAL FOREST LANDSCAPE

\begin{tabular}{|c|c|c|c|c|}
\hline \multicolumn{2}{|c|}{$\begin{array}{l}\text { Unidades de Paisagem } \\
\text { Landscape Units }\end{array}$} & \multirow{2}{*}{$\begin{array}{c}\text { Escala } \\
\text { temporo- } \\
\text { espacial } \\
\text { Time-Spatial } \\
\text { Scale } \\
1^{\text {a }} \text { Grandeza } \\
1^{\text {st }} \text { Grandeur }\end{array}$} & \multirow{2}{*}{$\begin{array}{c}\text { Exemplo tomado em } \\
\text { uma dada Paisagem } \\
\text { An Example } \\
\text { Zona Tropical } \\
\text { (Florestas Tropicais) }\end{array}$} & \multirow{2}{*}{\begin{tabular}{l}
\multicolumn{1}{c}{$\begin{array}{c}\text { Características Gerais } \\
\text { Several characteristics }\end{array}$} \\
Ligado ao conceito de zonalidade \\
planetária definida pelo clima e \\
pelo bioma e/ou mega-estruturas
\end{tabular}} \\
\hline \multirow{3}{*}{ 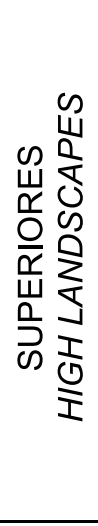 } & $\begin{array}{l}\text { ZONA } \\
\text { ZONE }\end{array}$ & & & \\
\hline & $\begin{array}{l}\text { DOMÍNIO } \\
\text { PLACE }\end{array}$ & $\begin{array}{l}2^{\text {a }} \text { Grandeza } \\
2^{\text {nd }} \text { Grandeur }\end{array}$ & $\begin{array}{l}\text { Domínio da Floresta } \\
\text { Tropical Atlântica }\end{array}$ & $\begin{array}{l}\text { Dado pelo relevo, climas mais } \\
\text { específicos e até pela vegetação, } \\
\text { não há restrição quanto ao } \\
\text { número de variáveis }\end{array}$ \\
\hline & $\begin{array}{l}\text { REGIÃO } \\
\text { NATURAL } \\
\text { NATURAL } \\
\text { REGION }\end{array}$ & $\begin{array}{l}3 \text { e } 4^{a} \\
\text { Grandeza } \\
3^{r d} \text { and } 4^{\text {th }} \\
\text { Grandeur }\end{array}$ & $\begin{array}{c}\text { Depressão Periférica } \\
\text { (Floresta Estacional } \\
\text { Semidecidual Atlântica } \\
\text { e Cerrado) }\end{array}$ & $\begin{array}{l}\text { Aspectos mais pontuais como a } \\
\text { variação altimétrica, com } \\
\text { interferência no clima e este por } \\
\text { sua vez na vegetação, bem como } \\
\text { solos e formações tectônicas } \\
\text { característicos }\end{array}$ \\
\hline \multirow{3}{*}{ 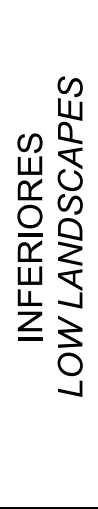 } & $\begin{array}{l}\text { GEOSSISTEMA } \\
\text { GEOSYSTEM }\end{array}$ & $\begin{array}{l}4 \text { e } 5^{a} \\
\text { Grandeza } \\
4^{\text {th }} \text { and } 5^{\text {th }} \\
\text { Grandeur }\end{array}$ & $\begin{array}{l}\text { Serra de Araçoiaba } \\
\text { com Mata Atlântica }\end{array}$ & $\begin{array}{l}\text { Acentua o complexo geográfico e } \\
\text { a dinâmica do conjunto } \\
\text { procurando as menores unidades } \\
\text { onde se verifica homogeneidade }\end{array}$ \\
\hline & $\begin{array}{l}\text { GEOFÁCIES } \\
\text { GEOFACES }\end{array}$ & $\begin{array}{l}6^{\text {a }} \text { Grandeza } \\
6^{\text {th }} \text { Grandeur }\end{array}$ & $\begin{array}{l}\text { Floresta Estacional } \\
\text { Semidecidual em } \\
\text { estágio inicial de } \\
\text { sucessão } \\
\end{array}$ & $\begin{array}{l}\text { Dado principalmente por aspectos } \\
\text { fisionomicamente homogêneos } \\
\text { com o desenvolvimento de uma } \\
\text { mesma fase de evolução geral }\end{array}$ \\
\hline & $\begin{array}{l}\text { GEÓTOPO } \\
\text { GEOTOP }\end{array}$ & $\begin{array}{l}7^{\text {a }} \text { Grandeza } \\
7^{\text {th }} \text { Grandeur }\end{array}$ & $\begin{array}{l}\text { Pequena área com } \\
\text { alguns indivíduos de } \\
\text { embauba }\end{array}$ & $\begin{array}{l}\text { A menor unidade geográfica } \\
\text { homogênea diretamente } \\
\text { discernível no terreno }\end{array}$ \\
\hline
\end{tabular}


Um outro exemplo de classificação das paisagens foi elaborado por Fávero $^{3}$, também considerando os argumentos encontrados no artigo de Bertrand (Quadro 2).

Para o Prof. Carlos Augusto de Figueiredo Monteiro, os termos geossistema, geofácies, geótopo, ecótopo, pedótopo, biótopo entre outros, deveriam ser substituídos apenas pelo termo "unidade de paisagem" acompanhado da escala, por exemplo, unidades de paisagens na escala 1:10.000, facilitando, portanto, a compreensão.

Das seis categorias de unidades da paisagem, Bertrand dá uma maior atenção para o geossistema, uma unidade compreendida entre alguns quilômetros quadrados e algumas centenas de quilômetros quadrados, afirmando ser esta escala a que guarda a maior parte dos fenômenos mais interessantes para o geógrafo, constituindo também em uma boa base para os estudos de organização por ser compatível com a escala humana. Esboçou uma interessante definição teórica de geossistema considerando-o como o resultado de relações entre o potencial ecológico, a exploração biológica e a ação antrópica.
A classificação da paisagem não pode ser considerada um fim em si, mas sim um passo seguido pela avaliação de cada unidade e, para tanto, Bertrand escolheu uma tipologia dinâmica que classifica as unidades da paisagem (mais especificamente os geossistemas) em função de sua evolução em relação ao clímax, tipologia inspirada na teoria de bio-resistasia de H. Erhart.

Por fim, o autor apresenta uma série de orientações para a representação cartográfica das paisagens, assunto imprescindível para todos os estudos geográficos relacionados com essa questão.

O esboço metodológico de Bertrand, apresenta uma Geografia Física Global que se nutre dos estudos especializados tradicionais procurando entender as combinações, a dinâmica e evolução das paisagens, e se abre para os problemas de organização do espaço.

Esse texto de Bertrand constitui, portanto, em mais um material básico que vem auxiliando na mudança da abordagem somente analítica e linear para uma abordagem com orientação sistêmica, sintética e integrativa, muito necessária nos dias atuais.

3 A Prof. Ms. Oriana Ap. Fávero concluiu sua dissertação de mestrado no Departamento de Geografia da USP com o título "Do berço da Siderurgia Brasileira à Conservação de Recursos Naturais - um estudo da Paisagem da Floresta Nacional de Ipanema, Iperó/SP" em 2002, mas não chegou a incluir esse quadro na dissertação e nem o publicou. Sendo assim, achamos conveniente a sua apresentação, como mais um exemplo de taxonomia da paisagem. 